\title{
Comparing the Usability and Acceptability of Wearable Sensors Among Older Irish Adults in a Real-World Context: Observational Study
}

Alison Keogh ${ }^{1}$, BSc, MSc, PhD; Jonas F Dorn ${ }^{2}, \mathrm{BSc}, \mathrm{PhD}$; Lorcan Walsh ${ }^{3}$, BSc, PhD; Francesc Calvo ${ }^{2}$, BSc, MSc; Brian Caulfield ${ }^{1}$, BSc, MSc, PhD

\author{
${ }^{1}$ Insight Centre for Data Analytics, UCD School of Public Health, Physiotherapy and Sports Science, University College Dublin, Dublin, Ireland \\ ${ }^{2}$ Data and Digital, Novartis Pharma AG, Basel, Switzerland \\ ${ }^{3}$ Data Sciences, Novartis Business Services, Dublin, Ireland
}

\section{Corresponding Author:}

Alison Keogh, BSc, MSc, PhD

Insight Centre for Data Analytics

UCD School of Public Health, Physiotherapy and Sports Science

University College Dublin

O'Brien Centre for Science, Science Centre East

Belfield

Dublin, 4

Ireland

Phone: 353863762075

Email: Alison.keogh@ucd.ie

\section{Abstract}

Background: Wearable devices are valuable assessment tools for patient outcomes in contexts such as clinical trials. To be successfully deployed, however, participants must be willing to wear them. Another concern is that usability studies are rarely published, often fail to test devices beyond 24 hours, and need to be repeated frequently to ensure that contemporary devices are assessed.

Objective: This study aimed to compare multiple wearable sensors in a real-world context to establish their usability within an older adult ( $>50$ years) population.

Methods: Eight older adults wore seven devices for a minimum of 1 week each: Actigraph GT9x, Actibelt, Actiwatch, Biovotion, Hexoskin, Mc10 Biostamp_RC, and Wavelet. Usability was established through mixed methods using semistructured interviews and three questionnaires, namely, the Intrinsic Motivation Inventory (IMI), the System Usability Scale (SUS), and an acceptability questionnaire. Quantitative data were reported descriptively and qualitative data were analyzed using deductive content analysis. Data were then integrated using triangulation.

Results: Results demonstrated that no device was considered optimal as all scored below average in the SUS (median, IQR; min- $\max =57.5,12.5 ;$ 47.5-63.8). Hexoskin was the lowest scored device based on the IMI (3.6; 3.4-4.5), while Biovotion, Actibelt, and Mc10 Biostamp_RC achieved the highest median results on the acceptability questionnaire (3.6 on a 6-point Likert scale). Qualitatively, participants were willing to accept less comfort, less device discretion, and high charging burdens if the devices were perceived as useful, namely through the provision of feedback for the user. Participants agreed that the purpose of use is a key enabler for long-term compliance. These views were particularly noted by those not currently wearing an activity-tracking device. Participants believed that wrist-worn sensors were the most versatile and easy to use, and therefore, the most suitable for long-term use. In particular, Actiwatch and Wavelet stood out for their comfort. The convergence of quantitative and qualitative data was demonstrated in the study.

Conclusions: Based on the results, the following context-specific recommendations can be made: (1) researchers should consider their device selection in relation to both individual and environmental factors, and not simply the primary outcome of the research study; (2) if researchers do not wish their participants to have access to feedback from the devices, then a simple, wrist-worn device that acts as a watch is preferable; (3) if feedback is allowed, then it should be made available to help participants remain engaged; this is likely to apply only to people without cognitive impairments; (4) battery life of 1 week should be considered as 
a necessary feature to enhance data capture; (5) researchers should consider providing additional information about the purpose of devices to participants to support their continued use.

(JMIR Mhealth Uhealth 2020;8(4):e15704) doi: 10.2196/15704

\section{KEYWORDS}

wearable technology; usability; mixed methods; user satisfaction

\section{Introduction}

\section{Background}

The technological advancements of recent years are challenging the traditional methods of data capture within clinical trials. In particular, the use of wearable technology offers unprecedented access to a variety of accurate, objective health care data that can be captured remotely, thus providing real-time access to large amounts of patient data [1,2]. Wearable devices are considered more convenient for participants by enabling them to collect data themselves, potentially resulting in improved protocol compliance and retention [3].

Given the relatively recent development of wearable devices, research has primarily focused on evaluating their clinical validity [4]. However, in order for these devices to be successfully incorporated into clinical trials, not only must they reliably capture accurate data, but critically, participants must be willing to wear and engage with them over a sustained period. The International Organization for Standardization defines usability as the effectiveness, efficiency, and satisfaction with which specified users achieve specified goals in particular environments [5]. To evaluate these components, researchers need to understand the barriers and facilitators to the participant's adherence with devices, to ensure that researchers do not inadvertently select clinically useful yet inappropriate devices, thus risking trial outcomes [6]. However, limited empirical evidence exists evaluating participant-centered usability of wearable devices within clinical trials [1], with wear-time and adherence rates used as proxy usability assessments. Furthermore, existing evaluations are limited by a focus on consumer-based products [7-10], short testing periods (ie, 24 hours or less) [11], the evaluation of a single wearable device only $[12,13]$, and by the use of either qualitative or quantitative methods of data collection (but not both); thus, limiting the researchers full understanding of the participant's experiences [14].

Given the increasing prevalence of chronic conditions, clinical trials that focus on cohorts of older adults will be a key focus of future research. Older adults often report of requiring assistance with technology $[10,15,16]$, making it important to investigate the experiences of older adults with various wearable devices, particularly in those which are intended for medical and research environments, to understand which devices participants prefer wearing, and whether any barriers to their use exist. In particular, it is important that industry partners and research groups, who plan to run clinical trials, test a variety of devices in real-life remote monitoring situations that mirror the contexts and environments in which trials may take place.

\section{Objectives}

Therefore, the primary aim of this study was to investigate the usability of a variety of wearable sensors in a real-world context by asking older adults to wear them in their home environment for a minimum of one week. Specifically, this was completed to establish the sensors' utility and usability, beyond data quality, from the participant's perspective and understand how these perceptions may affect their use in clinical trials.

\section{Methods}

\section{Study Design and Participants}

This was a six-week observational study that adopted mixed methods. No detailed inclusion or exclusion criteria existed; however, participants were required to be above 50 years of age, healthy, and fully independent in their daily lives. As this was an exploratory study, a power analysis was not undertaken. Eight participants from Dublin and the wider Wicklow and Kildare area, Ireland were recruited using purposive, convenience sampling through local flyers and existing connections between December 2017 and February 2018 to allow for comparisons of user experience, both between and within participants. Recruitment ceased once data saturation was reached in the qualitative analysis.

\section{Included Devices}

Seven, small, noninvasive wearable sensor devices, designed to track activity and sleep data were selected: Actigraph GT9X Link (Actigraph LLC), Actibelt (Trium), Actiwatch Spectrum Plus (Philips), Biovotion Everion (Biovotion), Hexoskin (Carre Technology), Mc10 Biostamp_RC (MC10 Inc), and Wavelet (Wavelet Health; Table 1). These specific devices were selected by the industry partners of this study who wished to assess the usability of devices that may be used to track physical activity in future clinical trials. Devices were selected to compare the range of locations and level of user interaction that are available on the market for this purpose. 
Table 1. Basic functional and usability information regarding the devices included within the study.

\begin{tabular}{|c|c|c|c|c|c|c|c|}
\hline Device (manufacturer) & Tethered to & Intended use & $\begin{array}{l}\text { User app } \\
\text { required }\end{array}$ & User interface & $\begin{array}{l}\text { Medical } \\
\text { grade }^{\mathrm{a}}\end{array}$ & Battery life $\mathrm{e}^{\mathrm{b}}$ & $\begin{array}{l}\text { Memory } \\
\text { capacity }\end{array}$ \\
\hline $\begin{array}{l}\text { Actigraph GT9X Link } \\
\text { (Actigraph LLC) [17] }\end{array}$ & Wrist & $\begin{array}{l}\text { Sleep, actigraphy, and } \\
\text { energy expenditure }\end{array}$ & Yes (optional) & Watch screen & Yes & 1 week & $4 \mathrm{~GB}$ \\
\hline Actibelt (Trium) [18] & $\begin{array}{l}\text { Waist (flex- } \\
\text { belt or leather } \\
\text { belt }\end{array}$ & Actigraphy & No & None & No & 3 months & $1800 \mathrm{~GB}$ \\
\hline $\begin{array}{l}\text { Actiwatch Spectrum Plus } \\
\text { (Philips) [19] }\end{array}$ & Wrist & Sleep and actigraphy & No & Watch screen & Yes & 1 week & $1 \mathrm{MB}$ \\
\hline $\begin{array}{l}\text { Biovotion Everion } \\
\text { (Biovotion) [20] }\end{array}$ & Upper arm & $\begin{array}{l}\text { Heart rate, respiratory } \\
\text { rate, actigraphy, skin } \\
\text { temperature, heart rate } \\
\text { variability, and oxygen } \\
\text { saturation }\end{array}$ & Yes & None & Yes & 24 hours & $\begin{array}{l}\text { Server-based } \\
\text { memory, } 3 \\
\text { days of data } \\
\text { capture on } \\
\text { device }\end{array}$ \\
\hline $\begin{array}{l}\text { Hexoskin (Carre Technol- } \\
\text { ogy) [21] }\end{array}$ & Torso & Heart rate and actigraphy & No & None & No & $>24$ hours & 600 hours \\
\hline $\begin{array}{l}\text { Mc10 Biostamp_RC } \\
\text { (Mc10 Inc) [22] }\end{array}$ & Upper thorax $^{\mathrm{c}}$ & Heart rate and actigraphy & No & None & Yes & $2-5$ days & $\begin{array}{l}\text { Server-based } \\
\text { memory, } 3 \\
\text { days of data } \\
\text { capture on } \\
\text { device }\end{array}$ \\
\hline $\begin{array}{l}\text { Wavelet (Wavelet } \\
\text { Health) [23] }\end{array}$ & Wrist & Sleep and actigraphy & Yes & None & No & 24-36 hours & Not reported \\
\hline
\end{tabular}

${ }^{\mathrm{a}}$ Defined by manufacturers according to the Food and Drug Administration and European guidelines.

${ }^{\mathrm{b}}$ As reported by the device manufacturer.

${ }^{\mathrm{c}}$ In this study only, other attachment points exist.

\section{Study Procedure}

At the entry point to the study, participants provided written informed consent, after which an opening interview was undertaken to establish their views on wearable technology in health and their previous experiences with wearable devices. Participants were then provided with a device and instructed to wear the device at all times (if possible, during their normal activities, except showering, for the duration of the week). Devices were worn for a full seven days each. The order of the devices was randomized to minimize bias. Depending on the device, participants were not required to interact with the device other than to charge them, if the device required. A week after the first testing session, participants returned their device and were provided with a new sensor. Participants were asked to complete three validated outcome measures (as described below); while semistructured interviews were completed at the end of each deployment week, so that feedback was provided specifically for each device independently. Upon completion of the study, participants completed a final semistructured interview, wherein they were asked about their overall perceptions of the included sensors within the study and which devices they preferred and why. Device deployment was randomized to limit the risk of bias.

\section{Data Collection and Outcome Measures}

\section{Quantitative Data Collection}

Brief demographics of the participants were collected (ie, sex, age, height, weight, and any previous experience with sensors).
In total, three questionnaires were given to each participant regarding each of the sensors.

- The Systems Usability Scale (SUS): It measures the usability of a device/system/technology [24-26]. It consists of a 10-item questionnaire with five response options for respondents from 1: strongly disagree to 5: strongly agree, resulting in a potential minimum score of 0 and a maximum of 100 .

- Intrinsic Motivation Inventory (IMI): IMI is a multidimensional questionnaire intended to assess the participant's experiences related to a target activity [27], in this case, wearing the wearable device. The instrument contains 22 items on a 7-point Likert scale, ranging from 1: not at all true to 7: very true. The measure assesses six subscales: interest/enjoyment, perceived competence, effort/importance, pressure/tension, value/usefulness, and perceived choice.

- Acceptability questionnaire by Jacucci et al [28]: Jacucci et al [28] aimed to assess users' acceptance of wearable devices across dimensions including comfort, fear of technology, and privacy. Participants were asked to rate the extent to which they agreed or disagreed with each of the 26-item statements on a 6-point Likert scale ranging from 1: completely disagree to 6: completely agree, on 10 individual subsections.

\section{Qualitative Data Collection}

The aim of the qualitative phase was to explore the participant's opinions of the devices and the factors they felt influenced their 
use of the same (interview guide provided in Multimedia Appendix 1). A female research physiotherapist (AK) with a $\mathrm{PhD}$ in behavior change (including two years of experience and training in qualitative research) and currently working in the area of digital health completed the semistructured interviews to extract more information from participants about certain aspects of the design or usability of the device. Interviews were completed in either participants' homes or place of work, depending on their preference. Scratch notes were taken by AK during the interviews, which were also audio-recorded and transcribed verbatim by AK. As the sample was purposively gathered, some participants were known to the researcher and thus, a rapport was already established. Participants were aware of the purpose of the research through the participant information leaflet and consent form they signed before participating. Before completing the research, AK had pilot tested each device to ensure they were set up correctly; thus, she witnessed experiences of some of the potential barriers and facilitators to their use.

\section{Data Analysis}

\section{Quantitative Data Analysis}

The SUS score was computed for each participant following standard scoring methodology [24]. Descriptive statistics were calculated to find out the median (IQR; min-max) result per device. To score the IMI, all negatively worded statements were inversely translated by subtracting the participant's score from eight. Following this, the average score for each of the six categories was calculated for each participant and group median (IQR; min-max) scores were calculated for each category for each device independently. A median result for the acceptability questionnaire was calculated per device, alongside a median result for each of its 10 subsections independently. In the absence of reference interpretations of the IMI and acceptability questionnaire, the midpoint of Likert scale was selected as the minimum level of acceptability of a device [29-32].

\section{Qualitative Data Analysis}

Deductive content analysis was undertaken for each of the transcribed texts using a realist approach, whereby the researcher assumed that the opinions of the participants reflected their true perceptions and should be taken as real [33]. A deductive content analysis was undertaken to categorize the participant's responses based on previous knowledge [34]. Specifically, literature has suggested that perceived usefulness, comfort, and ease of use are critical factors of usability [10,35-37], thus, these were selected as the categories for which the content of the transcribed audio recordings would be assessed. In addition, because the research question focused on understanding whether participants would accept using these devices within a clinical trial, this was pragmatically selected as an additional category. Following the steps outlined in previous research [35], the researcher (AK) familiarized herself with the texts and then identified the content which corresponded with each of the preidentified categories $[34,35]$. Data saturation was deemed to have occurred when no additional learnings regarding the devices and their features were identified under the selected categories. This analysis was then discussed with another member of the research team (BR), who was experienced in qualitative research, to ensure accuracy in coding. Specific quotations, which were deemed to represent the most important aspects of participants' experiences were selected for inclusion by AK and BR. Participant checking did not take place as part of this study, and transcripts were not provided to the participants.

\section{Data Integration}

A triangulation design was completed at the interpretation level of data analysis to provide a more complete picture of each device, to enhance the reliability of the study, and to support data saturation [38]. Specifically, a meta-matrix was created to facilitate comparisons of the results by presenting the quantitative data in tabular format alongside the summarized qualitative themes. For each sensor independently, all results were displayed on the same page, to determine whether there was convergence, partial convergence, discrepancy, or silence [39-42].

\section{Ethics Approval and Consent to Participate}

This study received ethical approval from the University College Dublin Human Ethics Committee (ref: LS-17-92-Caulfield). All participants provided written informed consent.

\section{Results}

\section{Demographic Information}

Participant demographic information can be found in Table 2 . Six participants reported feeling comfortable or very comfortable using technology. Three were wearing an activity tracker, while the remaining three had worn them in the past. The final two participants rated their technology comfort levels as medium, with no previous experiences of using wearable devices. All participants wore each of the seven devices, with the exception of Hexoskin. The reasons for which are outlined within the results. In addition, all participants reported wearing the devices at all times during the week, with the exception of Hexoskin. However, no formal assessment of adherence was completed. 
Table 2. Participant demographic information.

\begin{tabular}{ll}
\hline Characteristic & Value \\
\hline Gender (n) & 5 \\
Male & 3 \\
$\quad$ Female & $62(53-72)$ \\
Age (years), mean (range) & 3 \\
Level of education (n) & 4 \\
Third level & 1 \\
$\quad$ Secondary level & \\
$\quad$ Primary level & 4 \\
Employment status (n) & 4 \\
Retired & 4 \\
Employed & \\
Experience with wearable devices (n) & 6 \\
Yes (current or past) & 2 \\
No & \\
\hline
\end{tabular}

\section{Quantitative Results}

\section{System Usability Scale}

The median score for all devices on the SUS was 57.5 (IQR 12.5; min-max $=47.5-63.8$ ) out of a possible score of 100. None of the tested devices were deemed to be good by participants, as all seven achieved scores of less than 68 (30). Actibelt achieved the highest median result of 63.8 (IQR 12.5; min-max $=47.5-67.5$ ), while Hexoskin achieved the lowest median result of 47.5; min-max=37.5- 57.5 (Table 3 ). The results for all of the devices fall between the 10th and the 30th percentile, meaning that all were considered below average [24].

\section{Intrinsic Motivation Inventory}

The median score for all devices on the IMI was 4.6 (1.0; 3.6-5.2) on the 7-point Likert scale. No device achieved very high results (Table 3). Hexoskin was the only device to score below the midpoint of Likert scale (3.6; 3.4-4.5), suggesting that participants would not be autonomously motivated to wear this device.

\section{Acceptability Questionnaire}

The median score for all devices on the acceptability questionnaire was $3.5(0.5 ; 3.2-3.6)$. The highest median results were achieved by Biovotion, Actibelt, and Mc10 Biostamp_RC, with each achieving results of 3.6 on the 6-point Likert scale (Table 3). 
Table 3. Participants' self-reported usability of each device according to (1) Intrinsic Motivation Inventory, (2) System Usability Scale, and (3) Acceptability questionnaire.

\begin{tabular}{|c|c|c|c|c|c|c|c|}
\hline $\begin{array}{l}\text { Questionnaire } \\
\text { domains }\end{array}$ & $\begin{array}{l}\text { Actigraph, } \\
\text { median (IQR); } \\
\text { min-max }\end{array}$ & $\begin{array}{l}\text { Actibelt, } \\
\text { median (IQR); } \\
\text { min-max }\end{array}$ & $\begin{array}{l}\text { Actiwatch, } \\
\text { median (IQR); } \\
\text { min-max }\end{array}$ & $\begin{array}{l}\text { Biovotion, } \\
\text { median (IQR); } \\
\text { min-max }\end{array}$ & $\begin{array}{l}\text { Hexoskin }{ }^{\mathrm{a}} \text {, } \\
\text { median; } \\
\text { min-max }\end{array}$ & $\begin{array}{l}\text { Mc10, median } \\
\text { (IQR); } \\
\text { min-max }\end{array}$ & $\begin{array}{l}\text { Wavelet, } \\
\text { median (IQR); } \\
\text { min-max }\end{array}$ \\
\hline \multicolumn{8}{|c|}{ Intrinsic Motivation Inventory (n=22 questions; 7-point Likert scale) } \\
\hline Median & $\begin{array}{l}4.3(0.8) \\
3.9-5.4\end{array}$ & $\begin{array}{l}4.1(0.9) ; \\
3.3-5.1\end{array}$ & $\begin{array}{l}4.7(1.1) \\
3.0-5.4\end{array}$ & $\begin{array}{l}5.2(0.3) \\
4.0-5.5\end{array}$ & $\begin{array}{l}3.6 \\
3.4-4.5\end{array}$ & $\begin{array}{l}4.5(1.1) \\
1.7-5.6\end{array}$ & $\begin{array}{l}4.7(0.8) \\
4.3-5.1\end{array}$ \\
\hline Interest & $\begin{array}{l}3.5(1.4) \\
2.3-5.3\end{array}$ & $\begin{array}{l}3.4(1.3) \\
2.8-5.0\end{array}$ & $\begin{array}{l}4.5(1.8) \\
1.5-5.5\end{array}$ & $\begin{array}{l}6.0(1.0) \\
2.5-7.0\end{array}$ & $\begin{array}{l}3.5 \\
3.5-4.3\end{array}$ & $\begin{array}{l}3.5(1.0) \\
1.0-4.3\end{array}$ & $\begin{array}{l}5.3(0.6) \\
4.7-7.0\end{array}$ \\
\hline Competence & $\begin{array}{l}6.7(3.2) \\
2.7-7.0\end{array}$ & $\begin{array}{l}6.2(1.4) \\
5.3-7.0\end{array}$ & $\begin{array}{l}6.3(2.0) \\
4.7-7.0\end{array}$ & $\begin{array}{l}6.5(1.9) \\
3.4-7.0\end{array}$ & $\begin{array}{l}4.3 ; \\
4.0-4.3\end{array}$ & $\begin{array}{l}5.0(1.7) \\
3.6-7.0\end{array}$ & $\begin{array}{l}6.7(0.8) \\
3.0-7.0\end{array}$ \\
\hline Effort & $\begin{array}{l}3.3(2.9) \\
2.0-5.8\end{array}$ & $\begin{array}{l}3.8(2.5) \\
2.3-5.5\end{array}$ & $\begin{array}{l}3.5(3.0) \\
2.5-6.3\end{array}$ & $\begin{array}{l}3.9(1.6) \\
2.0-5.8\end{array}$ & $\begin{array}{l}3.5 \\
2.0-3.8\end{array}$ & $\begin{array}{l}4.3(2.8) \\
1.8-6.8\end{array}$ & $\begin{array}{l}4.0(1.3) \\
1.0-5.5\end{array}$ \\
\hline Pressure & $\begin{array}{l}1.3(2.0) \\
1.0-3.3\end{array}$ & $\begin{array}{l}1.0(0.3) \\
1.0-1.3\end{array}$ & $\begin{array}{l}1.0(2.0) \\
1.0-3.7\end{array}$ & $\begin{array}{l}1.8(1.7) \\
1.0-5.0\end{array}$ & $\begin{array}{l}3.3 ; \\
2.0-3.7\end{array}$ & $\begin{array}{l}3.0(3.0) \\
1.0-4.0\end{array}$ & $\begin{array}{l}2.0(2.8) \\
1.0-4.0\end{array}$ \\
\hline Choice & $\begin{array}{l}6.9(0.9) \\
6.0-7.0\end{array}$ & $\begin{array}{l}6.9(1.4) ; \\
3.0-7.0\end{array}$ & $\begin{array}{l}7.0(1.0) \\
5.5-7.0\end{array}$ & $\begin{array}{l}6.8(1.5) \\
5.3-7.0\end{array}$ & $\begin{array}{l}4.3 ; \\
4.0-7.0\end{array}$ & $\begin{array}{l}6.8(1.8) \\
1.5-7.0\end{array}$ & $\begin{array}{l}4.0(0.0) \\
3.3-4.0\end{array}$ \\
\hline Usefulness & $\begin{array}{l}4.9(2.5) \\
3.0-5.5\end{array}$ & $\begin{array}{l}3.9(2.1) \\
1.8-5.5\end{array}$ & $\begin{array}{l}5.5(3.0) \\
1.0-7.0\end{array}$ & $\begin{array}{l}6.1(1.7) \\
4.0-7.0\end{array}$ & $\begin{array}{l}3.0 \\
1.8-3.3\end{array}$ & $\begin{array}{l}5.0(2.3) \\
1.0-6.8\end{array}$ & $\begin{array}{l}6.8(0.9) \\
5.0-7.0\end{array}$ \\
\hline \multicolumn{8}{|c|}{ System Usability Scale (n=10 questions; 5-point Likert scale, score out of 100) } \\
\hline Total score & $\begin{array}{l}60.0(15.6) ; \\
50.0-67.5\end{array}$ & $\begin{array}{l}63.8(12.5) ; \\
47.5-67.5\end{array}$ & $\begin{array}{l}57.5(15.0) ; \\
50.0-65.0\end{array}$ & $\begin{array}{l}56.6(13.1) ; \\
45.0-70.0\end{array}$ & $\begin{array}{l}47.5 ; \\
37.5-57.5\end{array}$ & $\begin{array}{l}55.0(12.5) ; \\
45.0-65.0\end{array}$ & $\begin{array}{l}56.3(9.4) \\
50.0-62.5\end{array}$ \\
\hline \multicolumn{8}{|c|}{ Acceptability questionnaire (n=26 questions; 6-point Likert scale) } \\
\hline Median score & $\begin{array}{l}3.6(0.9) \\
2.8-5.2\end{array}$ & $\begin{array}{l}3.4(1.0) \\
2.8-4.7\end{array}$ & $\begin{array}{l}3.2(0.8) \\
3.0-4.0\end{array}$ & $\begin{array}{l}3.6(0.6) ; \\
3.0-4.8\end{array}$ & $\begin{array}{l}3.2 ; \\
3.0-3.5\end{array}$ & $\begin{array}{l}3.6(0.4) \\
3.0-3.9\end{array}$ & $\begin{array}{l}3.5(0.4) \\
3.2-4.0\end{array}$ \\
\hline Attitude & $\begin{array}{l}5.3(1.6) \\
3.7-6.0\end{array}$ & $\begin{array}{l}5.2(1.1) \\
4.7-6.0\end{array}$ & $\begin{array}{l}4.3(1.0) \\
4.0-6.0\end{array}$ & $\begin{array}{l}4.7(1.8) \\
3.3-6.0\end{array}$ & $\begin{array}{l}4.0 \\
3.3-4.7\end{array}$ & $\begin{array}{l}4.3(1.7) \\
4.0-5.7\end{array}$ & $\begin{array}{l}4.3(1.6) \\
3.7-6.0\end{array}$ \\
\hline Anxiety & $\begin{array}{l}1.8(2.5) \\
1.0-5.3\end{array}$ & $\begin{array}{l}1.8(2.6) \\
1.0-5.3\end{array}$ & $\begin{array}{l}2.7(1.7) \\
1.0-3.0\end{array}$ & $\begin{array}{l}2.5(2.9) \\
1.0-4.3\end{array}$ & $\begin{array}{l}2.7 \\
2.3-2.7\end{array}$ & $\begin{array}{l}3.0(1.0) \\
2.3-3.7\end{array}$ & $\begin{array}{l}2.3(1.8) \\
1.0-5.0\end{array}$ \\
\hline $\begin{array}{l}\text { Facilitating } \\
\text { conditions }\end{array}$ & $\begin{array}{l}2.5(4.8) \\
1.0-6.0\end{array}$ & $\begin{array}{l}2.5(2.6) \\
1.0-4.0\end{array}$ & $\begin{array}{l}1.5(1.0) ; \\
1.0-3.0\end{array}$ & $\begin{array}{l}2.5(2.3) \\
1.0-3.5\end{array}$ & $\begin{array}{l}5.5 ; \\
3.5-6.0\end{array}$ & $\begin{array}{l}3.0(4.5) ; \\
1.0-6.0\end{array}$ & $\begin{array}{l}1.5(1.0) \\
1.0-2.5\end{array}$ \\
\hline $\begin{array}{l}\text { Perceived } \\
\text { usefulness }\end{array}$ & $\begin{array}{l}4.5(2.7) \\
3.3-6.0\end{array}$ & $\begin{array}{l}3.5(2.3) \\
1.0-6.0\end{array}$ & $\begin{array}{l}4.3(2.3) \\
1.0-6.0\end{array}$ & $\begin{array}{l}4.8(1.5) \\
4.0-6.0\end{array}$ & $\begin{array}{l}2.3 \\
1.3-3.0\end{array}$ & $\begin{array}{l}3.3(2.7) \\
1.0-6.0\end{array}$ & $\begin{array}{l}5.2(1.0) \\
4.0-6.0\end{array}$ \\
\hline $\begin{array}{l}\text { Perceived } \\
\text { effort }\end{array}$ & $\begin{array}{l}3.8(3.0) \\
3.0-6.0\end{array}$ & $\begin{array}{l}3.8(1.5) \\
3.5-5.0\end{array}$ & $\begin{array}{l}3.5(0.0) \\
3.5-4.0\end{array}$ & $\begin{array}{l}4.5(2.3) \\
3.0-6.0\end{array}$ & $\begin{array}{l}5.0 \\
3.5-5.0\end{array}$ & $\begin{array}{l}3.5(1.0) \\
3.0-5.5\end{array}$ & $\begin{array}{l}3.5(0.5) \\
3.0-6.0\end{array}$ \\
\hline $\begin{array}{l}\text { Behavioral } \\
\text { intentions }\end{array}$ & $\begin{array}{l}3.5(1.4) \\
1.0-6.0\end{array}$ & $\begin{array}{l}3.0(1.2) \\
1.7-4.3\end{array}$ & $\begin{array}{l}3.7(1.0) \\
2.3-6.0\end{array}$ & $\begin{array}{l}3.8(0.8) \\
3.3-4.3\end{array}$ & $\begin{array}{l}2.7 \\
2.7-3.0\end{array}$ & $\begin{array}{l}3.0(1.7) \\
2.7-4.7\end{array}$ & $\begin{array}{l}3.8(1.2) \\
3.0-4.3\end{array}$ \\
\hline $\begin{array}{l}\text { Psychological } \\
\text { attachments }\end{array}$ & $\begin{array}{l}3.8(2.1) \\
1.5-6.0\end{array}$ & $\begin{array}{l}3.8(2.4) \\
1.0-6.0\end{array}$ & $\begin{array}{l}4.5(3.0) \\
3.0-6.0\end{array}$ & $\begin{array}{l}4.5(1.8) \\
2.5-6.0\end{array}$ & $\begin{array}{l}2.5 \\
1.5-3.5\end{array}$ & $\begin{array}{l}3.0(2.0) \\
1.0-6.0\end{array}$ & $\begin{array}{l}4.0(1.5) \\
1.5-5.0\end{array}$ \\
\hline Privacy & $\begin{array}{l}2.5(1.4) \\
1.0-5.0\end{array}$ & $\begin{array}{l}3.0(2.4) \\
1.0-6.0\end{array}$ & $\begin{array}{l}2.5(1.0) \\
1.0-5.0\end{array}$ & $\begin{array}{l}3.3(1.9) \\
1.0-4.5\end{array}$ & $\begin{array}{l}2.5 ; \\
2.5-3.0\end{array}$ & $\begin{array}{l}3.0(3.0) \\
1.0-6.0\end{array}$ & $\begin{array}{l}2.8(1.6) \\
1.0-4.0\end{array}$ \\
\hline Enjoyment & $\begin{array}{l}3.7(1.5) \\
2.7-4.7\end{array}$ & $\begin{array}{l}4.0(1.1) \\
2.0-4.3\end{array}$ & $\begin{array}{l}3.0(1.0) \\
2.7-3.7\end{array}$ & $\begin{array}{l}2.7(1.1) \\
2.0-4.3\end{array}$ & $\begin{array}{l}3.7 \\
3.0-4.3\end{array}$ & $\begin{array}{l}3.7(1.7) \\
1.7-5.0\end{array}$ & $\begin{array}{l}2.7(0.3) \\
1.0-3.0\end{array}$ \\
\hline Comfort & $\begin{array}{l}3.3(1.3) \\
2.0-5.3\end{array}$ & $\begin{array}{l}4.3(1.8) \\
2.3-4.3\end{array}$ & $\begin{array}{l}4.0(1.3) \\
2.7-4.3\end{array}$ & $\begin{array}{l}4.0(0.5) \\
3.7-4.7\end{array}$ & $\begin{array}{l}3.0 \\
2.3-4.0\end{array}$ & $\begin{array}{l}2.7(1.3) \\
2.0-4.3\end{array}$ & $\begin{array}{l}4.3(0.7) \\
2.7-5.0\end{array}$ \\
\hline
\end{tabular}

${ }_{n}{ }_{n}=3$ participants. Hexoskin was removed from the study after receiving the feedback from the first three participants to use it. The burden they reported was considered too high to ask any remaining participants to use it. Therefore, no IQR exists. 


\section{Qualitative Results}

Interviews per device ranged from 10-21 min in length. Exit interviews at the end of the study ranged from 18 to $38 \mathrm{~min}$ in length. The findings for each device under the headings of comfort of device, perceived usefulness of device, ease of use of device, and likelihood of wearing a device are provided throughout the results with supporting quotations (participant numbers listed in parentheses).

\section{Comfort of Devices}

Participants believed that wrist-worn sensors were the most versatile and easy to use, and therefore, the most suitable for long-term use. In particular, Actiwatch and Wavelet stood out for their comfort. Wavelet, in particular, was remarked to be similar in design to Fitbit, resulting in its acceptability. However, the clasp method of closing the watch was not secure unless carefully completed, resulting in one participant losing a device. Actigraph was the only watch-based device that received negative feedback under the heading of comfort. The bulkiness of the device, perceived outdated design, and the frequency with which it snagged in participants' clothes were the reasons for negative feedback.

Actibelt was perceived as surprisingly comfortable by all participants who expected it to be more cumbersome than it was. In contrast, Mc10 Biostamp_RC was notable for its lack of comfort. It was considered itchy. Participants noted that they were aware of Mc10 Biostamp_RC's potential to fall off, while female participants were aware that the device was visible underneath certain clothing:

\begin{abstract}
I just thought the most convenient and simplest one was the Wavelet. Well it was small, it was unobtrusive, it was a good design, it wasn't as bulky as the Actigraph and it just looked like a normal kind of Fitbit. [101, male, age 64 years, employed]

The ideal device is in a watch form because they are the easiest thing to wear, the ones that don't interfere with day to day activities as much and they don't interfere with what clothing you're wearing, unless they're very bulky. [401, female, age 56 years, employed]
\end{abstract}

\section{Ease of Use of Devices}

The devices that required little to no interaction from participants were considered the easiest to use (ie, Actibelt, Actiwatch, and Actigraph GT9X Link). Although Mc10 Biostamp_RC did not require participants to engage with it, once it was on, participants were required to change the adhesive stickers every 1-3 days, resulting in the uncertainty and concern about the accuracy of their replacements; thus, the accuracy of the data provided by the device. In response, participants used the red marks on their skin left by the devices as guides to help them:

Oh I didn't like the stamps [Mc10]... Well they were a bit fiddly to put on in the first place. They had the gel and it was hard to quite know the exact place to put them on, and then they can come off quite easily and then you have to put them back on... and then you have to take them on and off when you are having your shower, so they were almost completely impractical, certainly from a long-term point of view, you couldn't do that for more than a couple of days. [101, male, age 64 years, employed]

Wavelet and Biovotion provided participants with feedback through a mobile phone app, which was also the method required to monitor the battery level of the devices. For most participants this was not problematic, as the feedback provided by the device was interesting; therefore, engaging with the app was not a burden. However, the majority of participants agreed that long battery life was essential for long-term use of wearable devices, with a minimum of one week considered ideal. The need to charge a device daily was deemed unacceptable. Thus, this was a barrier to the sustained use of both Wavelet and Biovotion. One participant forgot to check the battery levels and as a result, missed the data collection of a number of days. In addition, Wavelet required users to select within the app, when they would go to sleep, resulting in an additional task, which was again, often forgotten:
Now perhaps if you have it for a long time you just purely get into the habit of doing it but it was very easy to forget because you know there's I suppose, bed time you should get into procedures because I do, I remember to charge things to do stuff. If there was something that was on the device itself even if it was a little button that says sleep. [601, male, age 52 years, employed]

The devices most difficult to use were also those that were the least favored. Specifically, Hexoskin was considered as an excessive burden on participants, as it required users to moisten the chest sensors within the vest frequently (every 15-20 min) to capture the heart and breathing rate data accurately. This was deemed impractical and disruptive to activities of daily living; therefore, a decision was made to cease the testing of the device, following the feedback from first three participants:

If you look at something like the vest [Hexoskin],
which was very irritating that you had to keep wetting
the sensors...I'd wear it for 24 hours but it's not
something that I would wear for a week and I
certainly wouldn't wear it for six weeks...No matter
the feedback...because it's just too limiting in your
day to day activity... having to reach around under
your breasts to find this piece of cloth that's a sensor
and then wet it is not something you can do easily in
a public place. [401, female, age 56 years, employed]

\section{Perceived Usefulness of Devices}

For the majority of participants, the best devices were those they felt they received the most feedback from (ie, Wavelet, Biovotion). Indeed, participants seemed willing to compromise on small annoyances if they were personally getting something from the device. The devices with little to no feedback were not perceived as useful, with some participants appearing indifferent to the devices owing to this reason (ie, Actibelt, Actiwatch GT9X Link, and Mc10 Biostamp_RC). Nonetheless, participants were able to understand how these devices may still be valuable to others, including clinicians and researchers, and thus, were prepared to wear these devices in the name of science: 
Well, because there was no feedback, it [Actiwatch] was pointless to me but in fairness to it was absolutely no trouble at all, you just forget it's there, its design is better [than the Actigraph]. As you can see, I'm wearing it on a wrist with another watch and it just wasn't an issue at all ... it played no part in my life at all...first of all it's just one piece, it's got, even though it not much of a beveled edge, it's got enough that things won't snag on it as much. I do find it just sits better on the wrist the strap seems to be softer, more malleable. [601, male, age 52 years, employed]

It's there and it has no function [Actibelt]. There's no feedback, there's no information, there's no feedback telling you what's happening. [301, female, age 62 years, employed]

Wavelet was reported to be the most useful device by participants who valued the simple graphs provided within the app (ie, sleep and heart rate). Actigraph GT9X Link was initially considered very basic, as the only information it provided was step count. Although, the participants did become accustomed to being able to easily check their step count throughout the day. Finally, even though Biovotion provided participants with innovative feedback (data were presented in an integrated spiral depicting a full day of information within a clock), the potential usefulness of future iterations of the device was greater than its current version. In particular, participants desired numerical data in addition to the spiral graph, to help them understand normal reference values. The suggestion by one participant that the device was ahead of its time is important, as it suggests that Biovotion is a promising product (dependent on future iterations) that may have a strong role to play in the monitoring of patient health:

I think it [Biovotion] was meant to measure things like your peripheral circulation or something, but again it gives you a number, it doesn't tell you whether that means that your peripheral circulation is good, bad or indifferent...otherwise it's just like a gimmick, it's there you've got this little spiral that's colourful, bit entertaining to look at...but you don't get a chart to show what it was at various times during the day unless you just interpret what the spiral is showing,...all you get is real-time readings...it seems to be like the ultra-high definition televisions when they came out, they were fantastic, they looked wonderful but you couldn't get ultra-high definition programs, so basically the televisions were head of its time. In a sense I think then maybe that this device is ahead of its time. [401, female, age 56 years, employed]

\section{Likelihood of Wearing a Device During a Trial}

Participants agreed that the purpose of use is a key enabler for long-term compliance. These views were particularly noted by those not currently wearing an activity-tracking device. Although these participants explained that they did not personally feel the need to track their own activities, they suggested that they would not object to wearing a device for longer periods (ie, 8-12 weeks). For instance, in situations if they had to (ie, in the context of a clinical trial or by a clinician) and if the device was reasonably comfortable and easy to use. For most devices, participants reported that they would only wear them only if it was necessary, suggesting that their use of these devices would be born out of compliance rather than a specific, intrinsically motivated intention:

I would find it bothersome [having to wear the Mc10 within a trial]...I would be willing to do it you know because I think it's good, but I was actually glad that today was the last day of these. [701, female, age 63 years, retired]

I would do it for the sake of science, and for this, but I certainly wouldn't, under no circumstances would I purchase it or use it kind of on an ongoing basis. [601, male, age 52 years, employed]

\section{Integrated Results}

Convergence was predominantly seen across each of the devices independently across the four headings: comfort, ease of use, usefulness, and likelihood of wearing the device. Specifically, an agreement could be observed between the qualitative and quantitative results overall; thus, providing support for each of the results. Table 4 provides a sample of this matrix, specifically for Actigraph GT9X Link. A full list of results for each individual sensor is available within Multimedia Appendix 2. 
Table 4. Matrix of integrated qualitative and quantitative data for Actigraph GT9X Link (this device was used as an example).

\begin{tabular}{|c|c|c|c|}
\hline $\begin{array}{l}\text { Outcome of } \\
\text { interest }\end{array}$ & Quantitative result, median (IQR); min-max & Qualitative result & $\begin{array}{l}\text { Convergence; } \\
\text { discrepancy; silence }\end{array}$ \\
\hline Comfort & $\begin{array}{l}\text { - Midpoint of the Likert scale for perceived } \\
\text { comfort (acceptability questionnaire): } 3.3 \\
\text { (1.3); 2.0-5.3 }\end{array}$ & $\begin{array}{l}\text { - } \quad \text { Somewhat comfortable } \\
\text { - } \quad \text { For some, along with excessive strap length, the device } \\
\text { irritated them to the point of being uncomfortable } \\
\text { - Others felt that despite the size, the device was } \\
\text { nonetheless comfortable }\end{array}$ & Convergence \\
\hline
\end{tabular}

Perceived

usefulness

Likelihood

of wearing a device
- $\quad$ Midpoint for interest (IMI $\left.{ }^{\mathrm{a}}\right)$ : 3.5 (1.4); 2.35.3

- $\quad$ Midpoint for usefulness (IMI): 4.9 (2.5) 3.0-5.5

- $\quad$ Midpoint for effort/importance (IMI): 3.3 (2.9); 2.0-5.8

- $\quad$ OK usability (SUS ${ }^{\mathrm{b}}$ ): 60.0 (15.6); 50.0-67.5

- High perceived usefulness (acceptability questionnaire): 4.5 (2.7); 3.3-6.0

- Midpoint enjoyment (acceptability questionnaire): 3.7 (1.5); 2.7-4.7 functionality

- Dual function as a watch appreciated
Convergence

Step count was both interesting and useful

Convergence

\footnotetext{
Ease of use

- High perceptions of competence (IMI): 6.7 (3.2); 2.7-7.0

- Midpoint for perceived effort (acceptability questionnaire): 3.8 (3.0); 3.0-6.0

- $\quad$ Midpoint for effort/importance (IMI): 3.3 (2.9); 2.0-5.8
}

- $\quad$ Low pressure to wear (IMI): 1.3 (2.0); 1.03.3

- $\quad$ High perceived choice (IMI): $6.9(0.9) ; 6.0-$ 7.0

- Midpoint behavioral intentions (acceptability questionnaire): 3.5 (1.4); 1.0-6.0

- Midpoint psychological attachments (acceptability questionnaire): 3.8 (2.1); 1.5-6.0

- Low facilitating conditions (acceptability questionnaire): 2.5 (4.8); 1.0-6.0

\section{-} there was little to no interaction required with it Limited difficulties reported
Partial convergence 
to the small sample size in this study, these results should be interpreted with caution, as they cannot be generalizable to the wider population. In addition, the participants in this study were familiar with technology, which may limit direct comparisons with other research. Nonetheless, the quantitative results may provide some useful insights regarding the potential for these devices to be used in clinical trials. Specifically, low scores in the SUS are common, even among popular consumer devices including Fitbit [46]. A trade-off between comfort and functionality appears to exist, whereby participants are willing to accept a slightly less comfortable device, provided it serves a purpose that they value [47]. This is evidenced by participants consistently repeating that they would accept small annoyances for a device they perceived as beneficial. Indeed, it has been suggested that the "function of any wearable tool must outweigh any physical or social discomfort felt in wearing it, and less desirable devices may meet with higher standards for comfort and fit." This finding echoes recent studies wherein participants were most likely to purchase and recommend devices based on their features, battery life, ease of use, and reliability [46,48-51]. Specifically, in relation to older adults, this study repeated the findings of previous research in that devices, which were deemed to be comfortable, fit seamlessly into daily routines, and demonstrated a clear perceived benefit to the participants were the devices that were favored [12,52]. Participants in this study consistently listed Wavelet and Biovotion as their preferred devices owing to the combination of useful feedback, comfort, and seamless interaction with their daily lives. However, the ability of participants to easily check the battery level of devices is a necessity, especially within a clinical trial wherein consistent data collection is paramount. Even though perceived usefulness and perceived ease of use are critical components for participants' intention to use a wearable device $[10,37]$, both Wavelet and Biovotion may be limited in the sense that their battery level needs to be regularly monitored by users.

Interestingly, participants have been shown to consistently select a favorite device, irrespective of the evidence they gather to refute this. This was mirrored in this study as participants overwhelmingly agreed that Actibelt was one of the most comfortable, least obtrusive devices, had the longest battery life, and yet consistently failed to list it as a favorite. The perceived importance of feedback is likely to be the sole reason for this discrepancy, therefore, highlighting one of the most important findings of this research: for participants to be motivated to wear a device, they must see a purpose for it. For example, Actibelt and Actiwatch were very comfortable to all participants; however, neither device provided feedback. As participants were not confident whether they understood what data were being collected, the devices were not considered useful by the participants. In contrast, Actigraph GT9X Link was cumbersome and bulky, yet its simple feedback made it a device that participants appreciated.

When the results of this study are combined with previous research $[10,12,46]$, it is clear that participants in multiple cohorts, both healthy and clinical, are broadly accepting of wearable technology, and once they can see the use of a relatively comfortable devices, they will be willing to wear them. However, one important insight that needs to be considered by both researchers and device manufacturers alike; participants are often able to see the future capability of wearable technology beyond its current function and are often left disappointed by the realities of a device when compared with the potential (eg, the measurement of blood pressure with Biovotion). Thus, research investigating the usability of wearable devices is consistently strengthening the argument that user-centered design is critical for compliance, and that users must gain some sort of advantage from wearing these devices. For most users, this is gained through the provision of feedback. Although, it remains unclear as to what level of feedback is considered necessary by participants, especially within cohorts with cognitive impairments. Given that many medical devices are not routinely designed to provide feedback, the result of this is a clash between health and consumer attributes in cohorts that desire and can cognitively interpret it [51]. Indeed, a common research hypothesis is that wearable devices may alter clinical trial outcomes because of real-time metrics and the ability of users to self-monitor their behavior [53]. However, sustained and meaningful behavior change has yet to be consistently demonstrated through consumer-based wearables alone [36,37,46,53]. Therefore, it should be considered whether feedback is a tangible risk to clinical trial outcomes. If it is not a risk, the provision of feedback may be one of the most important variables to consider when selecting a device for users without a cognitive impairment, as its presence provides participants with a perceived value for the device, which may support enhanced compliance. In response to this, researchers need to consider whether they can select a device that provides participants with some form of feedback (eg, heart rate), while remaining blind to the primary outcome measure of the trial (eg, physical activity). This is in regard to the acknowledgement that the future device development needs to incorporate desired participant functions to enhance compliance.

\section{Limitations}

The results of this study should be considered alongside its limitations. Firstly, the findings cannot be generalized to the wider population due to the small number of participants, specifically older adults, many of whom were comfortable with technology. Thus, the findings of this study cannot be widely generalizable. However, as technology becomes more pervasive, older participants will become accustomed to its use, and thus, understanding the experiences of those who are comfortable with technology is nonetheless useful. Indeed almost $80 \%$ of older adults in one study reported using some form of technology in their lives [13]; however, it must be acknowledged that the experiences of people in their mid-60s cannot be compared with those in their 70s or above [13]. Additionally, although eight participants is a small number, participants acted as their own controls by comparing the use of multiple devices, thus, providing valuable within-study comparisons. Furthermore, the clinical utility and accuracy of these devices was not evaluated as part of this study. However, since this study commenced, some manufacturers have, or are about to release new versions of these devices on the market (eg, Actigraph). In addition, no formal measure of wear-time was collected within this study. Therefore, the results rely on participants' self-report of whether they used the device or not. However, given that the 
focus of this study was on the usability of the device, compliance was not considered an important quantitative variable. For instance, in the case of Hexoskin, participants made it clear that they would not comply, and did not continue to wear the device due to its lack of usability. Given the aim of this study, this qualitative finding was more valuable than a quantitative measure of compliance as they highlighted the reasons why compliance was poor rather than simply whether it was or not. Finally, the result for Mc10 Biostamp_RC are likely to have been negatively influenced by the placement of the sensors on the pectoral muscles of participants, while Hexoskin is not intended for long-term monitoring. Future research should deploy the Mc10 Biostamp_RC device on alternative locations to determine whether the findings seen here are replicated. Since completing this study, the Biostamp_RC has been discontinued by Mc10 and has been replaced by Biostamp nPoint. Despite these limitations, the recommendations within this study may be of practical support for researchers considering which device to use within their trials.

\section{Conclusions}

By using mixed methods and testing each device for a week, this study gained a robust understanding of the complexities of selecting a device for use within a clinical trial. The results indicate that no single sensor was considered optimal by participants due to a variety of factors, including the feedback provided by the device, its comfort, and battery life. Participants favored devices that they perceived they gained value from and were willing to overlook annoyances to receive feedback. Based on these results, the following context-specific recommendations can be made:

1. Researchers should consider their device selection in relation to both individual and environmental factors and not simply the primary outcome of the research study.

2. If researchers do not wish their participants to have access to the feedback from the devices, then a simple, wrist-worn device that acts as a watch is preferable.

3. If feedback is allowed, then it should be made available to help keep participants engaged. This is likely to apply only to people without cognitive impairments.

4. Battery life of 1 week should be considered as a necessary feature to enhance data capture.

5. Researchers should consider providing additional information about the purpose of devices to participants to support their continued use.

\section{Acknowledgments}

The authors would like to thank Craig Marronn for his help with the data collection of this study, and Brenda Reginatto for her assistance with the qualitative analysis of this study. This study was funded by Novartis Pharma. Novartis funded the purchase of the tested devices within this study.

\section{Authors' Contributions}

JD, LW, FC, and BC outlined the study design and aim. AK collected and analyzed the data. All authors contributed to the final version of the manuscript. AK is the guarantor of the study.

\section{Conflicts of Interest}

JD, FC, and LW work for Novartis.

\section{Multimedia Appendix 1}

Interview guide.

[DOCX File, 19 KB-Multimedia Appendix 1]

\section{Multimedia Appendix 2}

Full list of tables of triangulated data per device. [DOCX File , 29 KB-Multimedia Appendix 2]

\section{References}

1. Rosa C, Campbell AN, Miele GM, Brunner M, Winstanley EL. Using e-technologies in clinical trials. Contemp Clin Trials 2015 Nov;45(Pt A):41-54 [FREE Full text] [doi: 10.1016/j.cct.2015.07.007] [Medline: 26176884]

2. Reeder B, David A. Health at hand: A systematic review of smart watch uses for health and wellness. J Biomed Inform 2016 Oct;63:269-276 [FREE Full text] [doi: 10.1016/j.jbi.2016.09.001] [Medline: 27612974]

3. Bates M. IEEE Pulse Magazine. 2016 Mar 14. New Trends in Clinical Trials URL: https://pulse.embs.org/march-2016/ new-trends-in-clinical-trials/ [accessed 2019-03-20]

4. Rosenberger M, Buman M, Haskell W, McConnell M, Carstensen LL. Twenty-four hours of sleep, sedentary behavior, and physical activity with nine wearable devices. Med Sci Sports Exerc 2016 Mar;48(3):457-465 [FREE Full text] [doi: 10.1249/MSS.0000000000000778] [Medline: 26484953]

5. International Organization for Standardization. ISO 13407:1999(en) Human-Centred Design Processes for Interactive Systems URL: https://www.iso.org/obp/ui/\#iso:std:iso:13407:ed-1:v1:en [accessed 2018-03-20] 
6. Borrelli B. The assessment, monitoring, and enhancement of treatment fidelity in public health clinical trials. J Public Health Dent 2011;71(Suppl 1):S52-S63. [doi: 10.1111/j.1752-7325.2011.00233.x] [Medline: 21656954]

7. Liang J, Xian D, Liu X, Fu J, Zhang X, Tang B, et al. Usability study of mainstream wearable fitness devices: feature analysis and System Usability Scale evaluation. JMIR Mhealth Uhealth 2018 Nov 8;6(11):e11066 [FREE Full text] [doi: 10.2196/11066] [Medline: 30409767]

8. Jia Y, Wang W, Wen D, Liang L, Gao L, Lei J. Perceived user preferences and usability evaluation of mainstream wearable devices for health monitoring. PeerJ 2018;6:e5350 [FREE Full text] [doi: 10.7717/peerj.5350] [Medline: 30065893]

9. Kaewkannate K, Kim S. A comparison of wearable fitness devices. BMC Public Health 2016 May 24;16:433 [FREE Full text] [doi: 10.1186/s12889-016-3059-0] [Medline: 27220855]

10. Mercer K, Giangregorio L, Schneider E, Chilana P, Li M, Grindrod K. Acceptance of commercially available wearable activity trackers among adults aged over 50 and with chronic illness: A mixed-methods evaluation. JMIR Mhealth Uhealth 2016 Jan 27;4(1):e7 [FREE Full text] [doi: 10.2196/mhealth.4225] [Medline: 26818775]

11. Gao Y, Li H, Luo Y. An empirical study of wearable technology acceptance in healthcare. Ind Manag Data Syst 2015;115(9):1704-1723. [doi: 10.1108/imds-03-2015-0087]

12. Farina N, Sherlock G, Thomas S, Lowry RG, Banerjee S. Acceptability and feasibility of wearing activity monitors in community-dwelling older adults with dementia. Int J Geriatr Psychiatry 2019 Apr;34(4):617-624. [doi: 10.1002/gps.5064] [Medline: 30701592]

13. McMahon SK, Lewis B, Oakes M, Guan W, Wyman JF, Rothman AJ. Older adults' experiences using a commercially available monitor to self-track their physical activity. JMIR Mhealth Uhealth 2016 Apr 13;4(2):e35 [FREE Full text] [doi: 10.2196/mhealth.5120] [Medline: 27076486]

14. Toomey E, Matthews J, Hurley DA. Using mixed methods to assess fidelity of delivery and its influencing factors in a complex self-management intervention for people with osteoarthritis and low back pain. BMJ Open 2017 Aug 4;7(8):e015452 [FREE Full text] [doi: 10.1136/bmjopen-2016-015452] [Medline: 28780544]

15. Denton F, Spencer B. Chronic health conditions: changing prevalence in an aging population and some implications for the delivery of health care services. Can J Aging 2010 Mar;29(1):11-21. [doi: 10.1017/S0714980809990390] [Medline: 20202262]

16. Schenkenfelder R, Selinger S. FFH Open Access Repository. 2016. A Comparison of Multiple Wearable Devices Regarding their User Experience During Running URL: http://ffhoarep.fh-ooe.at/bitstream/123456789/686/1/125_218_

Schenkenfelder FullPaper en Final.pdf [accessed 2020-02-18]

17. ActiGraph. ActiGraph GT9X Link URL: https://www.actigraphcorp.com/actigraph-link/ [accessed 2018-03-01]

18. Trium Analysis Online. URL: https://www.trium.de/ [accessed 2018-03-01]

19. Philips Respironics. Actiwatch Spectrum Plus URL: http://www.actigraphy.com/solutions/actiwatch/actiwatch-plus.html [accessed 2018-03-01]

20. Biovotion. URL: https://www.biovotion.com [accessed 2018-03-01]

21. Hexoskin Smart Shirts. URL: https://www.hexoskin.com [accessed 2018-03-01]

22. MC10: Wearable Healthcare Technology \& Devices. Our Products URL: https://www.mc10inc.com/our-products [accessed 2018-03-01]

23. Wavelet HI. California, USA. 2018 Mar. Wavelet Health URL: http://www.wavelethealth.com/ [accessed 2018-03-01]

24. Brooke J. Hell - Jens Oliver Meiert. SUS - A Quick and Dirty Usability Scale URL: http://hell.meiert.org/core/pdf/sus.pdf [accessed 2018-03-20]

25. Bangor A, Kortum P, Miller J. Determining what individual SUS scores mean: adding an adjective rating scale. J Usability Stud 2009 May;4(3):114-123 [FREE Full text]

26. O'Reilly M, Slevin P, Ward T, Caulfield B. A wearable sensor-based exercise biofeedback system: mixed methods evaluation of Formulift. JMIR Mhealth Uhealth 2018 Jan 31;6(1):e33 [FREE Full text] [doi: 10.2196/mhealth.8115] [Medline: 29386171]

27. Centre for Self-Determination Theory. Intrinsic Motivation Inventory (IMI) URL: http://www.selfdeterminationtheory.org/ questionnaires/10-questionnaires/50 [accessed 2018-03-20]

28. Orso V, Gamberini L, Guardigli E, Spagnolli A, Varotto A. Measuring User Acceptance of Wearable Symbiotic Devices: Validation Study across Application Scenarios. In: Proceedings of the International Workshop on Symbiotic Interaction. 2014 Presented at: Symbiotic'14; October 30-31 2014; Helsinki, Finland p. 87-98. [doi: 10.1007/978-3-319-13500-7]

29. Tessier D, Sarrazin P, Ntoumanis N. The effect of an intervention to improve newly qualified teachers' interpersonal style, students motivation and psychological need satisfaction in sport-based physical education. Contemp Educ Psychol 2010;35(4):242-253. [doi: 10.1016/j.cedpsych.2010.05.005]

30. Bryant C, Lewis P, Bennell K, Ahamed Y, Crough D, Jull G, et al. Can physical therapists deliver a pain coping skills program? An examination of training processes and outcomes. Phys Ther 2014 Oct;94(10):1443-1454. [doi: 10.2522/ptj.20130444] [Medline: 24903113]

31. Nadler J, Weston R, Voyles E. Stuck in the middle: the use and interpretation of mid-points in items on questionnaires. J Gen Psychol 2015;142(2):71-89. [doi: 10.1080/00221309.2014.994590] [Medline: 25832738] 
32. Keogh A, Matthews J, Segurado R, Hurley D. Feasibility of training physical therapists to deliver the theory-based self-management of osteoarthritis and low back pain through activity and skills (SOLAS) intervention within a trial. Phys Ther 2018 Feb 1;98(2):95-107. [doi: 10.1093/ptj/pzx105] [Medline: 29088437]

33. Braun V, Clarke V. Using thematic analysis in psychology. Qual Res Psychol 2006 Jan;3(2):77-101. [doi: 10.1191/1478088706qp063oa]

34. Elo S, Kyngäs H. The qualitative content analysis process. J Adv Nurs 2008 Apr;62(1):107-115. [doi: 10.1111/j.1365-2648.2007.04569.x] [Medline: 18352969]

35. Puri A, Kim B, Nguyen O, Stolee P, Tung J, Lee T. User acceptance of wrist-worn activity trackers among community-dwelling older adults: mixed method study. JMIR Mhealth Uhealth 2017 Nov 15;5(11):e173 [FREE Full text] [doi: 10.2196/mhealth.8211] [Medline: 29141837]

36. Lee J, Kim D, Ryoo HY, Shin BS. Sustainable wearables: wearable technology for enhancing the quality of human life. Sustainability 2016;8(5):466 [FREE Full text] [doi: 10.3390/su8050466]

37. Lunney A, Cunningham N, Eastin M. Wearable fitness technology: a structural investigation into acceptance and perceived fitness outcomes. Comput Human Behav 2016;65(5):114-120. [doi: 10.1016/j.chb.2016.08.007]

38. Fusch PI, Ness LR. Are we there yet? Data saturation in qualitative research. Qual Rep 2015;20(9):1408-1416 [FREE Full text]

39. O'Cathain A, Murphy E, Nicholl J. Three techniques for integrating data in mixed methods studies. Br Med J 2010 Sep 17;341:c4587. [doi: 10.1136/bmj.c4587] [Medline: 20851841]

40. Hanson WE, Creswell JW, Clark VL, Petska KS, Creswell JD. Mixed methods research designs in counseling psychology. J Couns Psychol 2005;52(2):224-235 [FREE Full text] [doi: 10.1037/0022-0167.52.2.224]

41. Ivankova NV, Creswell JW, Stick SL. Using mixed-methods sequential explanatory design: from theory to practice. Field Methods 2006;18(1):3-20 [FREE Full text] [doi: 10.1177/1525822x05282260]

42. Driscoll D, Appiah-Yeboah A, Salib P, Rupert DJ. Merging qualitative and quantitative data in mixed methods research: how to and why not. Ecol Environ Anthropol 2007;3(1):19-28 [FREE Full text]

43. Rupp MA, Michaelis JR, McConnell DS, Smither JA. The role of individual differences on perceptions of wearable fitness device trust, usability, and motivational impact. Appl Ergon 2018 Jul;70:77-87. [doi: 10.1016/j.apergo.2018.02.005] [Medline: 29866329]

44. Karamanoğlu A, Erbug C. Perceived Qualities of Smart Wearables: Determinants of User Acceptance. In: Proceedings of the 2011 Conference on Designing Pleasurable Products and Interfaces. 2011 Presented at: DPPI'11; June 22 - 25, 2011 ; Milan, Italy p. 1-8 URL: http://dl.acm.org/citation.cfm?doid=2347504.2347533 [doi: 10.1145/2347504.2347533]

45. Sauro J. MeasuringU. 2011 Feb 2. Measuring Usability With the System Usability Scale (SUS) URL: https://measuringu. com/sus/ [accessed 2018-03-20]

46. Steinert A, Haesner M, Steinhagen-Thiessen E. Activity-tracking devices for older adults: comparison and preferences. Univ Access Inf Soc 2018;17(2):411-419. [doi: 10.1007/s10209-017-0539-7]

47. Bodine K, Gemperle F. Effects of Functionality on Perceived Comfort of Wearables. In: Proceedings of the Seventh IEEE International Symposium on Wearable Computers. 2003 Presented at: ISWC'03; October 21-23, 2003; White Plains, NY, USA URL: http://ieeexplore.ieee.org/document/1241394/ [doi: 10.1109/iswc.2003.1241394]

48. Williamson B, Aplin T, de Jonge D, Goyne M. Tracking down a solution: exploring the acceptability and value of wearable GPS devices for older persons, individuals with a disability and their support persons. Disabil Rehabil Assist Technol 2017 Nov;12(8):822-831. [doi: 10.1080/17483107.2016.1272140] [Medline: 28100086]

49. Nascimento B, Oliveira T, Tam C. Wearable technology: What explains continuance intention in smartwatches? J Retail Consum Serv 2018;43:157-169 [FREE Full text] [doi: 10.1016/j.jretconser.2018.03.017]

50. Sultan N. Reflective thoughts on the potential and challenges of wearable technology for healthcare provision and medical education. International Journal of Information Management 2015 Oct;35(5):521-526. [doi: 10.1016/j.ijinfomgt.2015.04.010]

51. Zhang M, Luo M, Nie R, Zhang Y. Technical attributes, health attribute, consumer attributes and their roles in adoption intention of healthcare wearable technology. Int J Med Inform 2017 Dec;108:97-109. [doi: 10.1016/j.ijmedinf.2017.09.016] [Medline: 29132639]

52. Farina N, Lowry R. Older adults' satisfaction of wearing consumer-level activity monitors. J Rehabil Assist Technol Eng 2017;4:2055668317733258 [FREE Full text] [doi: 10.1177/2055668317733258] [Medline: 31186939]

53. Patel M, Asch D, Volpp K. Wearable devices as facilitators, not drivers, of health behavior change. J Am Med Assoc 2015 Feb 3;313(5):459-460. [doi: 10.1001/jama.2014.14781] [Medline: 25569175]

\section{Abbreviations \\ IMI: Intrinsic Motivation Inventory \\ SUS: System Usability Scale}


Edited by G Eysenbach; submitted 31.07.19; peer-reviewed by N Farina, L Cilar; comments to author 21.10.19; revised version received 15.11.19; accepted 28.01.20; published 20.04.20

Please cite as:

Keogh A, Dorn JF, Walsh L, Calvo F, Caulfield B

Comparing the Usability and Acceptability of Wearable Sensors Among Older Irish Adults in a Real-World Context: Observational Study

JMIR Mhealth Uhealth 2020;8(4):e15704

URL: http://mhealth.jmir.org/2020/4/e15704/

doi: $10.2196 / 15704$

PMID: $\underline{32310149}$

(C)Alison Keogh, Jonas F Dorn, Lorcan Walsh, Francesc Calvo, Brian Caulfield. Originally published in JMIR mHealth and uHealth (http://mhealth.jmir.org), 20.04.2020. This is an open-access article distributed under the terms of the Creative Commons Attribution License (https://creativecommons.org/licenses/by/4.0/), which permits unrestricted use, distribution, and reproduction in any medium, provided the original work, first published in JMIR mHealth and uHealth, is properly cited. The complete bibliographic information, a link to the original publication on http://mhealth.jmir.org/, as well as this copyright and license information must be included. 